\title{
Perspective
}

\section{Establishing an enteric bacteria reference laboratory in Sierra Leone}

\author{
Marie Anne Chattaway ${ }^{1}$, Abdul Kamara ${ }^{2}$, Fay Rhodes ${ }^{2}$, Konneh Kaffeta ${ }^{2}$, Amara Jambai ${ }^{3}$, \\ Wondimagegnehu Alemu ${ }^{4}$, Mohammed Sirajul Islam ${ }^{5}$, Molly M Freeman ${ }^{6}$, William Welfare ${ }^{1}$, Doris \\ Harding $^{2}$, Ahmed F Samba ${ }^{2}$, Musu Abu ${ }^{2}$, Sylvester Kamanda ${ }^{2}$, Kathie Grant ${ }^{1}$, Claire Jenkins ${ }^{1}$, Satheesh \\ Nair $^{1}$, Steve Connell ${ }^{1}$, Lisa Siorvanes ${ }^{1}$, Sarika Desai ${ }^{1}$, Collette Allen ${ }^{1}$, Margaret Frost ${ }^{1}$, Daniel Hughes ${ }^{1}$, \\ Zonya Jeffrey ${ }^{1}$ Noel Gill ${ }^{1}$, Mark Salter ${ }^{1}$
}

${ }^{1}$ Public Health England, United Kingdom

${ }^{2}$ Central Public Health Reference Laboratory, Sierra Leone

${ }^{3}$ Directorate of Prevention and Control, Sierra Leone

${ }^{4}$ World Health Organisation, Country Office, Uganda

${ }^{5}$ Global Outbreak Response Alert Network consisting of International Centre of Diarrhoeal Disease Research, Bangladesh

${ }^{6}$ Centers for Disease Control and Prevention, United States

\begin{abstract}
In 2012, Sierra Leone experienced its worst cholera outbreak in over 15 years affecting 12 of the country's 13 districts. With limited diagnostic capability, particularly in bacterial culture, the cholera outbreak was initially confirmed by microbiological testing of clinical specimens outside of Sierra Leone. During 2012 - 2013, in direct response to the lack of diagnostic microbiology facilities, and to assist in investigating and monitoring the cholera outbreak, diagnostic and reference services were established in Sierra Leone at the Central Public Health Reference Laboratory focusing specifically on isolating and identifying Vibrio cholerae and other enteric bacterial pathogens. Sierra Leone is now capable of confirming cholera cases by reference laboratory testing.
\end{abstract}

Key words: Cholera; Sierra Leone; enteric disease; Salmonella; Shigella.

J Infect Dev Ctries 2014; 8(7):933-941. doi:10.3855/jidc.5074

(Received 04 April 2014 - Accepted 09 June 2014)

Copyright $(C 2014$ Chattaway et al. This is an open-access article distributed under the Creative Commons Attribution License, which permits unrestricted use, distribution, and reproduction in any medium, provided the original work is properly cited.

\section{Background to cholera and diarrhoeal disease in developing countries}

Diarrhoeal disease is a major global public health problem and affects populations in the developing world especially, causing illness and death among young children [1,2]. Despite improving trends in mortality rates, 1 in 10 deaths during the first five years of life are from diarrhoeal diseases and a total of approximately 800,000 deaths occur each year worldwide, mostly in sub Saharan Africa and South Asia [1,2].

Cholera is a non-invasive diarrhoeal disease caused by the rod shaped Gram negative bacterium Vibrio cholerae. Epidemics are caused by serogroups $\mathrm{O} 1$ and O139, of which the O1 serogroup can be further subdivided into serotypes Ogawa and Inaba, and biotypes classical and El-Tor [3]. Transmission of cholera is via the faecal-oral route. Due to its short incubation period ( 2 hours to 5 days) many epidemics happen in an explosive manner. Most cholera episodes are mild to moderate and clinically indistinguishable from other causes of acute diarrhoea [4].

There are an estimated 3-5 million cases of cholera that occur globally every year resulting in 100,000 120,000 deaths mainly in Africa and South Asia. The mortality rate is 6.3 per 100,000 people at risk in endemic countries. Reported cases probably only represent $5-10 \%$ of the true number of annual worldwide cases $[4,5]$.

The 7th cholera pandemic arrived in Africa in the early 1970s and since then has become endemic and a public health issue in many African countries. Approximately 1.3 million cases were reported to WHO between 2005-2012 with over 30,000 deaths [614]. 
Many developing countries lack the capability to perform basic microbiological testing for gastrointestinal pathogens which has major implications for disease diagnosis, outbreak detection, disease monitoring and the ability to assess the effectiveness of interventions and accurately measure burden of disease. All of these are important in tackling the causes of diarrhoeal disease.

\section{Background to cholera epidemiology in Sierra Leone}

Sierra Leone, a West African Country of just over 6 million people (http://hdrstats.undp.org), experienced its worst cholera outbreak in 15 years in 2012. The Human Development Index for Sierra Leone in 2012 was $0.359,177$ th out of 187 countries and territories. In Sierra Leone, life expectancy at birth is only 48 years, heavily influenced by one of the highest under 5 mortality rates (182 per 1000 live births WHO Global Health Observatory 2012 [15].

Sierra Leone has a surveillance system in place for cholera but data were previously based on clinicians reporting diarrhoeal disease and suspected cholera cases based on typical clinical presentation. Sierra Leone adopted the Integrated Disease Surveillance and Response (IDSR) strategy in 2004. The surveillance case definitions for cholera used in Sierra Leone are outlined in Table 1. An increase in the weekly number of cases of acute diarrhoea and vomiting (996 cases in 2011 as compared to 266 cases in 2010) was noted by the Ministry of Health and Sanitation (MoHS) in November 2011 in the Western Area (the most populous district that includes Freetown, the capital city). Initial investigations suggested $E$. coli was the causative agent.

In February 2012, the situation worsened (2134 cases for the three districts: Port Loko, Kambia and Pujehun), resulting in a joint investigation by MoHS and WHO. Vibrio cholerae O1 Ogawa was confirmed by the WHO regional laboratory in Burkina Faso and an outbreak of cholera was declared in the coastal district of Kambia.

With the onset of the rainy season, both the number of diarrhoeal cases and the districts affected began to increase (8200 cases between weeks 32, 33,
Figure 1. Spread of cholera in Sierra Leone in 2012 at the peak of the outbreak.

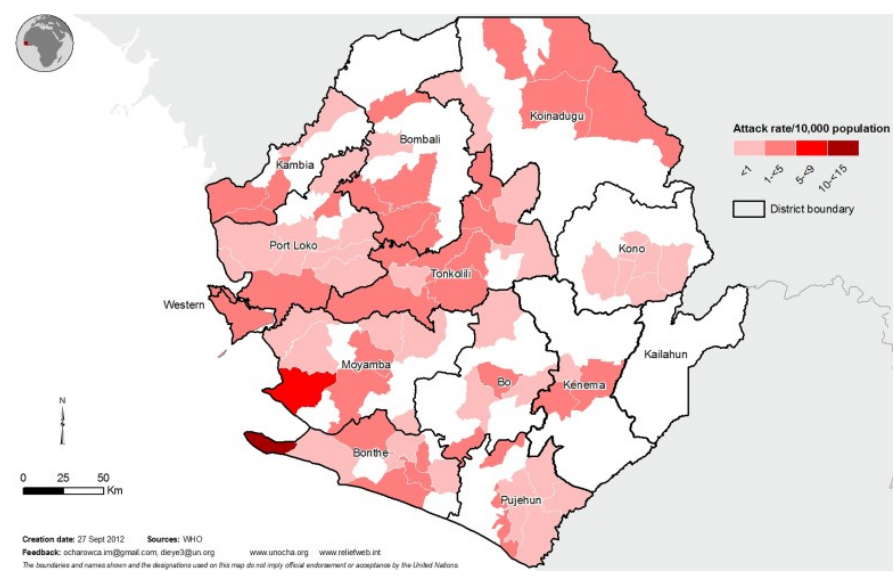

and 34). Samples collected in the Western Area were again confirmed by the WHO regional laboratory in Burkina Faso as V. cholerae O1 Ogawa. On the 17th August 2012, the President of Sierra Leone declared the cholera outbreak as a public health emergency.

By the end of 2012, there were 22, 969 cases and 299 deaths (Case Fatality ratio $(\mathrm{CFR})=1.30$ ), affecting 12 out of the 13 districts in Sierra Leone. The Western Area, the most populated district, reported more than $50 \%$ of the cases. Figure 1 shows the distribution of cases at the peak of the outbreak in week 38 .

Cholera outbreak in Sierra Leone - The need for Laboratory testing and systems

Due to a lack of trained, enteric microbiology laboratory staff in Sierra Leone, initially, it was necessary to send clinical specimens from suspected cholera cases to outside of the country. However, this arrangement could not be sustained long term and highlighted the urgent need for Sierra Leone to develop an independent cholera testing facility. Once the outbreak was confirmed as cholera, the initial focus was on identifying and characterising isolates of $V$. cholerae, eventually other common bacterial enteric pathogens prevalent in developing countries, such as Salmonella and Shigella species, were also included.

Table 1. Surveillance case definitions for Cholera in Sierra Leone

\begin{tabular}{ll}
\hline Category & Case Definition \\
\hline $\begin{array}{l}\text { Suspected case (when there is not an } \\
\text { outbreak) }\end{array}$ & $\begin{array}{l}\text { Any person aged 5 years of age or more who develops severe dehydration or dies from acute } \\
\text { watery diarrhoea }\end{array}$ \\
$\begin{array}{l}\text { Suspected case (when there is an } \\
\text { outbreak) }\end{array}$ & Any person aged 5 years of age or more with acute watery diarrhoea, with or without vomiting \\
Confirmed case & A suspected case in which Vibrio cholerae O1 or O139 has been isolated in the stool \\
\hline
\end{tabular}




\section{Methodology}

In order to develop a reliable and accurate diagnostic and reference laboratory service for enteric pathogens, a two phase process of training and testing was developed. This incorporated technical testing in line with standard laboratory safety guidelines and a quality based system according to ISO 15189 Strengthening Laboratory Management Towards Accreditation (SLMTA). The latter being a tool kit developed to promote immediate and measurable improvement in laboratories in developing countries [16] and recommended by the African Society for Laboratory Medicine (http://www.aslm.org).

The initial training (Phase 1) was based on emergency procedures where staff were trained on basic techniques in a short period of time. Training was concentrated on developing skills required for the detection and identification of $V$. cholerae in order to identify epidemic strains of cholera. Laboratory tests carried out in Central Public Health Reference Laboratory (CPHRL), Lakka, between November 2012 and February 2013 were based on Phase 1 training methods.

Phase 2 training involved a six month microbiological training programme of diagnostic and reference testing of a wider range of enteric bacterial pathogens including $V$. cholerae, E. coli (including O157) Salmonella spp (including $S$. Typhi) and speciation of Shigella boydii, $S$. dysentariae, $S$. flexneri and $S$. sonnei. A set of known enteric bacterial strains was used as positive controls to quality control all media and reagents and also used during training sessions to compare tests results against known reactions.

Testing of samples at CPHRL from March 2013 onwards was based on Phase 2 training methods.

\section{Microbiological Set Up}

Processing and Reporting Systems

Clinicians were asked to notify suspected cholera cases to District Surveillance Officers and to take a rectal swab using Cary Blair swabs (VWR Jencons, Lutterworth, UK). A specimen request form was devised to accompany these specimens.

Cary Blair was chosen as the most appropriate transport media as it maintains the viability of $V$. cholerae and other enteric bacteria without refrigeration for a number of days. Rectal swabs were transported to the CPHRL, assigned a unique laboratory reference number prior to microbiological analysis. Results were reported weekly to the Directorate of Prevention and Control (DPC)

Figure 2. Processing system flow chart (rectal swab collection to reporting)

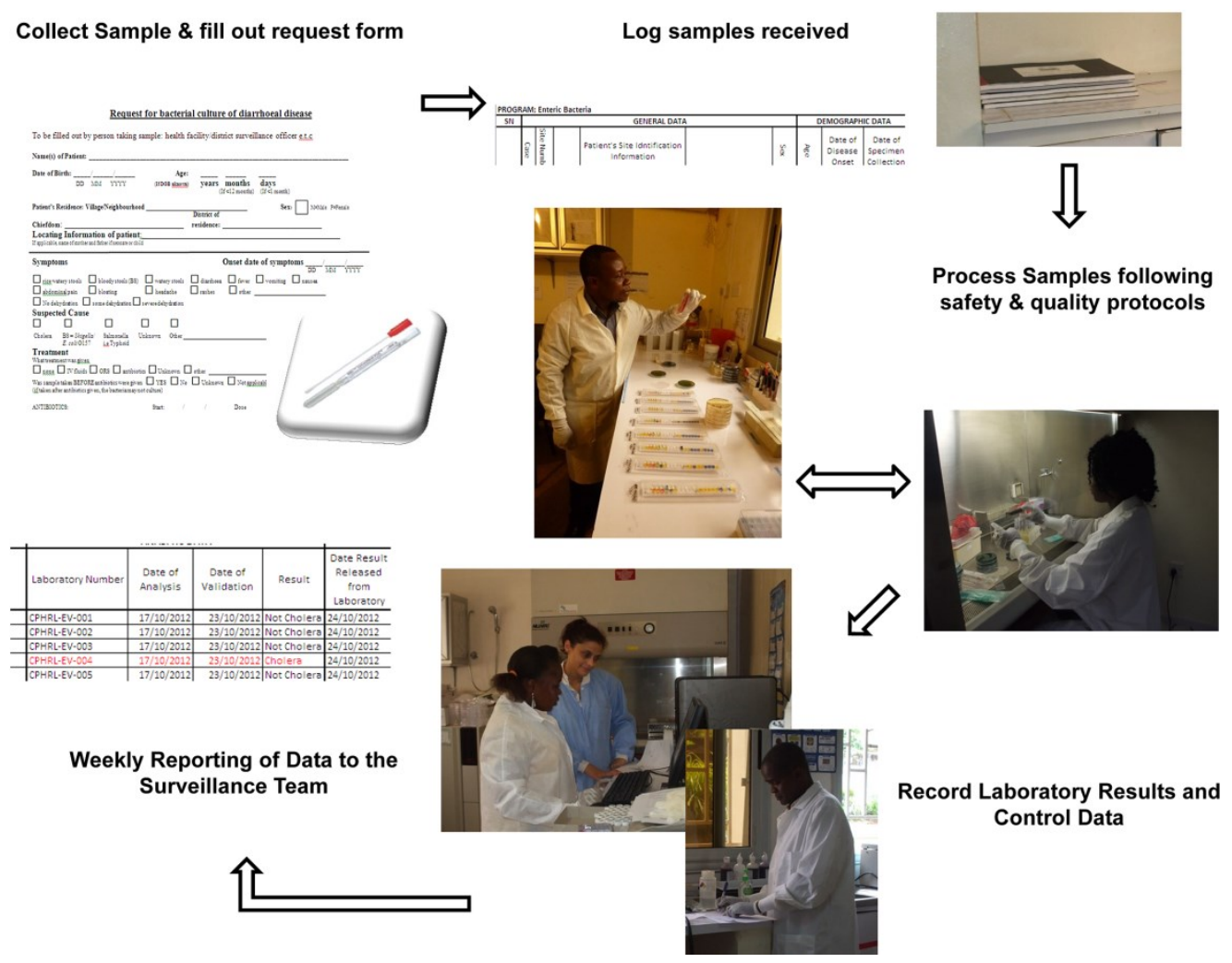


surveillance team. All processes were recorded on controlled documents and batches of media and reagents were tested with internal quality controls (IQCs) to ensure accuracy of results. All records were recorded in duplicate on both paper based and electronic systems. A flow chart of the laboratory processing from rectal swab collection to reporting is summarised in Figure 2

\section{Microbiological Testing}

Swabs were plated out for single colonies on relevant selective agar media (details below) and also used to inoculate selective enrichment broths designed to inhibit the growth of other bacteria whilst enriching the pathogen of interest. Inoculated broths were incubated aerobically overnight at $37^{\circ} \mathrm{C}$ and then plated onto the relevant selective media. Following incubation these plates were examined, if direct plating failed to yield a suspect pathogen or yielded insufficient colonies for testing, colonies from the enrichment broths were used. Colonies of interest from the selective media were sub-cultured onto Tryptone Soya Agar (TSA) (Oxoid, Basingstoke, UK) for further testing. Suspected $V$. cholerae samples were isolated and identified using standard techniques including alkaline peptone water (APW), Thiosulfate Citrate Bile Salts Sucrose (TCBS) agar, oxidase test and O1/ O139/Ogawa/Inaba serotyping [17] (Supplementary Figure 1). Suspected Salmonella species were isolated and identified using standard techniques including selenite enrichment broth, Xylose Lysine Deoxycholate (XLD) agar, oxidase test and Salmonella serotyping (Supplementary Figure 2). Suspected Shigella species were isolated and identified using standard techniques, including MacConkey (MAC) agar, oxidase test and Shigella serotyping (Supplementary Figure 2). E. coli were also isolated from MAC and slide agglutinations performed with O157 antisera [18,19].

Confirmed isolates were archived either on Vibrio stabs or dorset egg agar slopes (PHE Media, London, UK) at room temperature and also on microbeads and at $-20^{\circ} \mathrm{C}$ (Prolab, Wirral, UK). For Phase 2 testing, colonies positive by slide agglutinations were inoculated into API 20E strips, incubated overnight at $37^{\circ} \mathrm{C}$ and the profile interpreted according to the manufacturer's instructions (bioMérieux, Craponne, France).

During Phase 2 testing, positive and negative controls were used to test every batch of media agar plates and all reagents used for biochemical and serological testing of isolates. This is particularly important in developing countries where electricity can be sporadic, impacting the appropriate storage of laboratory reagents and media ingredients and ultimately compromising their quality.

\section{Quality Assurance}

All systems adopted by CPHRL were in accordance with Stepwise Laboratory Improvement Process Towards Accreditation (SLIPTA) using SLIPTA guidance [20]. Training records were devised for all members of staff to record their training activities. All documents; risk assessments and standard operating procedures were assigned CPHRL quality controlled version reference numbers.

All media received and used had batch numbers and expiry dates recorded, freshly prepared media were assigned batch numbers and quality tested with positive controls. All reagents used were also tested with controls and results recorded for every batch of tests performed. All equipment was monitored and temperatures recorded. Any errors were recorded and investigated, tests were repeated if necessary. Data were recorded on quality controlled laboratory books and electronic databases.

\section{Safety}

Risk assessments and a safety manual were written for the procedures and implemented before any laboratory work was carried out. Hand washing before leaving the enteric laboratory was strictly implemented and personal protective equipment (PPE) including laboratory coats and gloves were used for all laboratory procedures. A microbiological safety cabinet was used for handling primary clinical specimens; potential aerosol producing manipulation and any suspected containment level 3 organisms $(E$. coli $\mathrm{O} 157)$. Good laboratory practice when handling clinical specimens and microbiological cultures was established as the standard in the laboratory and was continuously assessed for compliance. Safety material including PPE, liquid soap, paper towels, safety signs, first aid kits, safety labels, biohazard incineration bags and disposal bins was provided before staff started work in the enteric laboratory.

\section{Training}

First phase (4 weeks): An intense multi-method approach was used for training staff in laboratory procedures including, one to one practical sessions, group discussions, lectures, homework and culminated with three day practical and theory exams. A basic enteric microbiological technique certificate was 
awarded to laboratory staff who successfully completed the examinations.

Second phase (6 months): An advanced six month development programme / curriculum was developed building on the multi-method approach and final three day advanced theory and practical exam. Four biomedical scientists from Public Health England (PHE) reference and hospital laboratories were seconded to CPHRL for four weeks each, over a six month period to carry out laboratory training. In between these secondments CPHRL staff were assigned to carry out weekly blind internal quality assessments of isolates to test and build on skills. An advanced enteric microbiological technique certificate was awarded to staff who completed the curriculum and passed both the theory and practical exams.

\section{Communications}

Update reports were communicated between PHE and CPHRL via email and when necessary by telephone. Communications between CPRHL and DPC were established via weekly electronic reporting of results from CPHRL and presented at the weekly cholera task force meetings.

\section{Results}

Microbiological Testing

During Phase 1 testing (using selective media, oxidase and serotyping for $V$. cholerae), 120 samples were processed between November 2012 and February 2013 (17 from the Western Area, 38 from the Southern Area, 44 from the Eastern Area and 21 from the Northern Area). Four presumptive $V$. cholerae $\mathrm{O} 1$ colonies were isolated from different samples. Clinical strain EB23 contained three yellow TCBS colonies, two presumptive $V$. cholerae colonies were correctly identified, though only one was $\mathrm{O} 1$ positive, the third colony was Aeromonas hydrophilia. Two of three further presumptive isolates were correctly identified; the third was identified as Vibrio fluvialis (Table 2).

During Phase 2 testing (with the addition of API $20 \mathrm{e}$ kits and testing for multiple enteric pathogens), 258 samples were processed between March 2013 and August 2013 (137 from the Western Area, 32 from the Southern Area, 18 from the Eastern Area and 71 from the Northern Area). Eight presumptive isolates of $V$. cholerae, E. coli, Shigella and Salmonella were identified by CPHRL and confirmed as being correct at the Gastrointestinal Bacteria Reference Unit, PHE (Table 2).

The addition of biochemical identification methods enabled more accurate identification of pathogens and the ability to eliminate commensal flora. All of the original samples sent were retested and only the true positives were selected by CPHRL for confirmation testing. Accuracy of identification by CPHRL improved with the correct identification of all isolates sent to PHE.

\section{Safety and Quality Assurance}

Safe systems of practice were successfully set up and staff continually worked in a safe manner with the emphasis on the importance of hand washing when working with enteric samples. Quality systems at CPHRL have been put in place and will continue to improve according to ISO 15189 guidelines with a view to gaining accreditation.

\section{Training}

Phase one: Four staff from CPHRL were trained in the basic identification of $V$. cholerae and passed both the theory and practical exams. Eight staff were trained in quality and safety in the laboratory and all passed the theory exam.

Phase two: Between the first and second phase testing there was a two month gap during which the CPHRL lab was without continuous external expertise and support and dedicated CPHRL staff were not assigned to the enteric section. This led to a number of issues for example, lack of supply source for consumables for the enteric laboratory and major interruptions to the electricity supply to the laboratory which affected the continuous running of fridges and incubators. It also became evident that laboratory skills had been lost and routine testing of clinical samples ceased.

To rectify this problem, PHE in collaboration with the MoHS and WHO provided volunteer staff from the UK, consumables and financial support for a six month period. These resources facilitated the assignment of two dedicated staff to run the enteric section, the ability to access locally available consumables and funding became available to provide fuel to run the electricity generator at CPHRL. Two staff were trained in isolation and identification of multiple enteric organisms and passed the advanced theory exam as well as correctly identifying all isolated organisms. Training for the advanced practical exam was severely affected by the lack of a constant electrical supply and staff were unable to complete this aspect of the programme. A further eight staff were trained in quality and safety in the laboratory and all passed the advanced theory exam. 
Table 2. Clinical and epidemiological information about enteric bacteria isolated between November 2012 and September 2013 by the Central Public Health

Reference Laboratory in Sierra Leone with confirmation testing by Public Health England.

\begin{tabular}{|c|c|c|c|c|c|c|c|}
\hline Date received at $\mathrm{PHE}$ & $\begin{array}{l}\text { CPHRL } \\
\text { Ref }\end{array}$ & District & $\begin{array}{l}\text { CPHRL } \\
\text { Phase + }\end{array}$ & $\begin{array}{l}\text { Clinician } \\
\text { presumptive } \\
\text { ID } \\
\end{array}$ & $\begin{array}{l}\text { Clinical } \\
\text { Symptoms }\end{array}$ & CPHRL ID & Reference ID by PHE \\
\hline 19.03.2013 & $\begin{array}{l}\text { EB0023- } \\
1 *\end{array}$ & $\begin{array}{l}\text { Eastern/ Kenema } \\
\text { City }\end{array}$ & 1 & Cholera & Not stated & $\begin{array}{l}\text { Vibrio cholerae } \\
\text { (Weak reaction with O1 Sera) }\end{array}$ & $\begin{array}{l}\text { Vibrio cholerae } \\
\text { Serotype: non } \mathrm{O} 1, \mathrm{O} 139\end{array}$ \\
\hline 19.03.2013 & $\begin{array}{l}\text { EB0023- } \\
2^{*}\end{array}$ & $\begin{array}{l}\text { Eastern/ Kenema } \\
\text { City }\end{array}$ & 1 & Cholera & Not stated & $\begin{array}{l}\text { Vibrio cholerae } \\
\text { (Weak reaction with O1 Sera) }\end{array}$ & Aeromonas hydrophilia \\
\hline 19.03.2013 & $\begin{array}{l}\text { EB0023- } \\
3 *\end{array}$ & $\begin{array}{l}\text { Eastern/ Kenema } \\
\text { City }\end{array}$ & 1 & Cholera & Not stated & $\begin{array}{l}\text { Vibrio cholerae } \\
\text { Serotype: O1 Ogawa }\end{array}$ & $\begin{array}{l}\text { Vibrio cholerae } \\
\text { Serotype: O1 Ogawa } \\
\text { Biotype: El Tor }\end{array}$ \\
\hline 19.03.2013 & EB0054 & Southern/ Bo & 1 & $\begin{array}{l}\text { Cholera \& } \\
\text { Shigella/E. } \\
\text { coli O157 }\end{array}$ & $\begin{array}{l}\text { RWS,BS, V,AP, } \\
\text { SD }\end{array}$ & $\begin{array}{l}\text { Vibrio cholerae } \\
\text { (Weak reaction with O1 Sera) }\end{array}$ & Vibrio fluvialis \\
\hline 19.03.2013 & EB0091 & Northern/ Kambia & 1 & Cholera & $\begin{array}{l}\text { RWS,D,F, } \\
\text { V,AP,H }\end{array}$ & Vibrio cholerae Serotype: O1 Inaba & $\begin{array}{l}\text { Vibrio cholerae } \\
\text { Serotype O1 Inaba } \\
\text { Biotype: El Tor }\end{array}$ \\
\hline 19.03.2013 & EB095 & Northern/ Tonkolili & 1 & Unknown & $\begin{array}{l}\text { RWS,D,F, } \\
\text { V,AP }\end{array}$ & $\begin{array}{l}\text { Vibrio cholerae } \\
\text { Serotype O1 Ogawa }\end{array}$ & $\begin{array}{l}\text { Vibrio cholerae } \\
\text { Serotype: O1 Ogawa } \\
\text { Biotype: El Tor }\end{array}$ \\
\hline 30.08 .2013 & EB271 & Western & 2 & Cholera & WS, V & E. coli & $\begin{array}{l}\text { E. coli } \\
\text { Serotype: O unidentifiable }\end{array}$ \\
\hline 30.08 .2013 & EB91 & Northern/ Kambia & 2 & Cholera & $\begin{array}{l}\text { RWS,D,F, } \\
\text { V,AP,H }\end{array}$ & Vibrio cholerae Serotype: O1 Inaba & $\begin{array}{l}\text { Vibrio cholerae } \\
\text { Serotype: O1 Inaba } \\
\text { Biotype: El Tor }\end{array}$ \\
\hline 30.08 .2013 & EB095 & Northern/ Tonkolili & 2 & Unknown & $\begin{array}{l}\text { RWS,D,F, } \\
\text { V,AP }\end{array}$ & $\begin{array}{l}\text { Vibrio cholerae } \\
\text { Serotype O1 Ogawa }\end{array}$ & $\begin{array}{l}\text { Vibrio cholerae } \\
\text { Serotype: O1 Ogawa } \\
\text { Biotype: El Tor }\end{array}$ \\
\hline 30.08 .2013 & EB23 & $\begin{array}{l}\text { Eastern/ Kenema } \\
\text { City }\end{array}$ & 2 & Cholera & Not stated & Vibrio cholerae Serotype: O1 Ogawa & $\begin{array}{l}\text { Vibrio cholerae } \\
\text { Serotype: O1 Ogawa } \\
\text { Biotype: El Tor }\end{array}$ \\
\hline 30.08 .2013 & EB279 & $\begin{array}{l}\text { Western/ Western } \\
\text { Urban }\end{array}$ & 2 & Salmonella & $\begin{array}{l}\text { BS, WS, D, F, } \\
\text { AP, SD }\end{array}$ & Shigella flexneri & $\begin{array}{l}\text { Shigella flexneri } \\
\text { Serotype: } 2 \mathrm{~b}\end{array}$ \\
\hline 30.08 .2013 & $\mathrm{~EB} 255$ & $\begin{array}{l}\text { Western/ Western } \\
\text { Urban }\end{array}$ & 2 & Unknown & $\mathrm{D}, \mathrm{F}, \mathrm{V}, \mathrm{AP}, \mathrm{R}$ & Salmonella sp & $\begin{array}{l}\text { Salmonella Havana } \\
\text { Serotype: I13,23f,g }\end{array}$ \\
\hline 02.09 .2013 & EB274 & $\begin{array}{l}\text { Western/ Western } \\
\text { Urban }\end{array}$ & 2 & Unknown & WS,F,V, N ND & Salmonella sp & $\begin{array}{l}\text { Salmonella Java } \\
\text { Serotype: I4,5,12:b:1 } 2 \\
\text { Phage type: RDNC }\end{array}$ \\
\hline 02.09 .2013 & EB254 & $\begin{array}{l}\text { Western/ Western } \\
\text { Urban }\end{array}$ & 2 & Unknown & $\begin{array}{l}\text { WS,D,F } \\
\text { V,R,SD }\end{array}$ & Salmonella sp & $\begin{array}{l}\text { Salmonella Enteritidis } \\
\text { Serotype: I9,12:g m } \\
\text { Phage type: RDNC }\end{array}$ \\
\hline
\end{tabular}

*Multiple colonies were tested some of which gave which cross-reactive agglutinations with the Vibrio cholerae O1 sera.
+Phase 1 (November 2012- February 2013) involved testing using the oxidase test and Vibrio cholerae serology for presumptive identification.

Phase 2 (March - August 2013) involved the addition of the API 20 e tests to confirm for reference standord tidetifiction

Clinical Symptoms: RWS-rice watery stools, BS-bloody stools, WS-watery stools, D-diarrhoea, F-fever, V-vomiting, N-nausea, AP-abdominal pain, H-headache, R-rashes, ND-no dehydration, SD-some dehydration, SVD-Severe dehydration

Phage Type: RDNC - Recognised but does not conform (i.e. reacts with phages but does not match a recognised reference pattern for typing) 


\section{Communications}

The DPC and CPHRL in Sierra Leone set up a communication system where samples from each district are collected by district surveillance officers and sent to CPHRL to confirm suspected cholera cases. CPHRL reports the results of confirmed cases of cholera weekly to the surveillance team.

\section{Discussion}

The aim of this project was to set up a functional diagnostic and reference laboratory services for enteric bacterial pathogens in Sierra Leone. Efforts were initially focussed on establishing emergency services for $V$. cholerae testing in response to the 2012 cholera epidemic, but it became clear there was an ideal opportunity to develop laboratory testing for other common gastrointestinal bacteria pathogens. A number of key learning issues were identified during the initial set up and training programme which may be valuable to others in similar situations

This project highlighted the importance of continuous training and support following the emergency response to the cholera outbreak. Assessment of the impact of a two month gap between the first and second phases of the training program emphasised how quickly initial training skills can be lost without continuous practice and the importance of engaging and monitoring the development of laboratory staff once the emergency period is over. The commitment to further support the initial training provided the staff opportunities to develop problem solving skills including the recognition of ambiguous laboratory testing results. For example following Phase 1 training, staff were able to identify the cholera epidemic strain but were reporting false positive serogroup $\mathrm{O} 1$ agglutination results due to cross reactions with the anti-sera. Following Phase 2, training staff were able to differentiate between weak and strong agglutination reactions.

Microbiological testing of $V$. cholerae is still in its infancy in Sierra Leone and therefore action to improve sanitation in hot spot areas will still continue to be based on current surveillance systems until a reliable network of laboratory confirmation is in place.

Sierra Leone has diarrhoeal surveillance, but with the exception of $V$. cholerae, is not pathogen specific. Request forms sent to CPHRL did sometimes indicate other pathogens such as Shigella or Salmonella spp. as being the causative agent but this is likely to be based on the clinician's knowledge of pathogens and/or assumptions of typical association (i.e. bloody diarrhoea was assumed to be associated with Shigella spp.in some cases).

The main issue encountered in setting up new laboratory systems was frequent disruptions to the electricity power supply. This resulted in reagents becoming inactivated. The introduction of positive control organisms ensured that reagents were able to be validated on a regular basis, before being used for every batch of tests. The inconsistent power supply also prevented clinical samples and laboratory tests from being incubated at the optimal temperature for bacterial growth, which had adverse consequences on the isolation and identification of enteric bacteria.

A further issue was the quality of the clinical samples collected. Whilst rectal swabs were requested to be taken and training and instructions were provided, it is possible that anal swabs were sometimes collected instead. Ideally, faecal samples should be tested within 24 hours, however, this was rarely possible due to transport and other logistical issues. Cary Blair swabs in transport media were used for specimen collection; these can be kept at room temperature (usually around $23^{\circ} \mathrm{C}$ ) for several days and maintain enteric pathogen viability. In Sierra Leone, room temperature can be equivalent to the optimal temperature for bacteria growth (ie $>30^{\circ} \mathrm{C}$ ) enabling commensal or contaminating bacteria to proliferate. The distance between specimen collection and the CPHRL together with the lack of paved roads meant that sometimes specimens were not tested within a few days but after longer periods. Often patients were treated with antibiotics and it is possible that clinical specimens were taken after treatment. The highest rate of $V$. cholerae recovery was from samples where no antibiotic treatment was given (data not shown). These difficulties might explain cases where the patient had classical rice water stools but $V$. cholerae was not isolated (see EB54 in Table 2). An instruction sheet regarding sample collection and negative results was provided to clinicians to encourage sample collection prior to antibiotic administration. It is important to note that microbiological results were not intended for patient management (as the patient would have been treated before the sample reaches CPHRL) but for national surveillance purposes. The collection of clinical specimens from diarrhoeal patients was a new concept in Sierra Leone and had not been performed routinely prior to the cholera outbreak. It is therefore important to feedback results to the clinicians to enhance clinical knowledge and encourage further engagement. 


\section{Conclusions}

CPHRL has a functioning enteric diagnostic laboratory and is now capable of identifying $V$. cholerae, E. coli (including serogroup O157), Salmonella $s p$ and speciation of Shigella boydii, $S$. dysentariae, S. flexneri and S. sonnei. Using microbiological identification is vital in supporting clinical definitions of cholera to obtain accurate number of cholera cases and important to develop for future diagnostics, surveillance and target hotspots to implement control and preventative methods.

CPHRL is working towards ISO15189 accreditation which is a necessary requirement if the laboratory is to continue to work at a high standard and produce accurate, reliable results. The next steps are for CPHRL to gain full accreditation status and to start rolling out training to hospital laboratories in other districts. Ultimately, the goal is to have a network of laboratories capable of performing front line presumptive identification of enteric bacteria and subsequently sending those isolates to CPHRL for reference confirmation. Ideally, reference centres could also be established in the Eastern, Southern and Northern areas of Sierra Leone so that clinical specimens can be processed in a timely manner thus improving the isolation of bacterial enteric pathogens.

\section{Acknowledgements}

Acknowledgements to the staff from the following organisations for their support and advice:

Ministry of Health and Sanitation (MoHS), Sierra Leone Foday Dafae, Sahr Gevao, Donald Taqi, Roland Conteh World Health Organisation (WHO), Sierra Leone - Teniin Gakuruh, Pamela Mitula, Michael Ndolie, Ishata Conteh, Alex Chimbaru, Charles Mugero, Naba Kamara

Public Health England (PHE), UK Layi Onakunle, Elizabeth De Pinna, Anthony Kessel, Maria Zambon, Kenny Yap, Monica Sethi, Dawn Hedges, Vivienne DoNascimento Centers for Diseases Control and Prevention (CDC), USA Ishata Wurie (Based in Sierra Leone)

Global Outbreak and Response Alert Network (GOARN), Geneva - Pat Dury, Khristeen Umali Dalangin.

UK Department for International Development (DFID), Sierra Leone - Susan Mshana, Uzoamaka Gilpin and Martin Walshe

University of Haverford, USA - Iruka Okeke

\section{Funding}

This project was funded by the Health Protection Agency and its successor, Public Health England. Thank you to WHO for providing the transportation and support as well as the MoHS and other organisations who have contributed in developing laboratory testing. Thank you to WHO, DFID and other organisations who funded building of CPHRL and provided equipment, thereby laying a foundation to which this project could build upon.

Thank you to the MoHS in Sierra Leone for their enthusiasm and input, to the healthcare workers who are taking the samples and to the WHO Regional Office for Africa (AFRO).

Thank you to all of the other organisations contributing to fighting cholera in Sierra Leone and improving healthcare systems in developing countries. Thank you to the UN Office for the Coordination of Humanitarian Affairs and WHO for permission to print their data (Figure 1).

\section{References}

1. Liu L, Johnson HL, Cousens S, Perin J, Scott S, Lawn JE, Rudan I, Campbell H, Cibulskis R, Li M, Mathers C, Black RE (2012) Global, regional, and national causes of child mortality: an updated systematic analysis for 2010 with time trends since 2000. Lancet 379: 2151-2161.

2. Kotloff KL, Nataro JP, Blackwelder WC, Nasrin D, Farag TH, Panchalingam S, Wu Y, Sow SO, Sur D, Breiman RF, Faruque AS, Zaidi AK, Saha D, Alonso PL, Tamboura B, Sanogo D, Onwuchekwa U, Manna B, Ramamurthy T, Kanungo S, Ochieng JB, Omore R, Oundo JO, Hossain A, Das SK, Ahmed S, Qureshi S, Quadri F, Adegbola RA, Antonio M, Hossain MJ, Akinsola A, Mandomando I, Nhampossa T, Acacio S, Biswas K, O'Reilly CE, Mintz ED, Berkeley LY, Muhsen K, Sommerfelt H, Robins-Browne RM, Levine MM (2013) Burden and aetiology of diarrhoeal disease in infants and young children in developing countries (the Global Enteric Multicenter Study, GEMS): a prospective, case-control study. Lancet 382: 209-222.

3. Kaper JB, Morris JG, Jr., Levine MM (1995) Cholera. Clin Microbiol Rev 8: 48-86.

4. WHO (2014) WHO CHOLERA. Fact Sheet. 107: http://www.who.int/mediacentre/factsheets/fs107/en/. Accessed $4^{\text {th }}$ June 2014.

5. Ali M, Lopez AL, You YA, Kim YE, Sah B, Maskery B, Clemens J (2012) The global burden of cholera. Bull World Health Organ 90: 209-218A.

6. WHO(2006) Weekly epidemiological Record. 81: 297-308. http://www.who.int/cholera/statistics/en/. Accessed $4^{\text {th }}$ June 2014.

7. WHO(2007) Weekly epidemiological Record. 82: 273-284. http://www.who.int/cholera/statistics/en/. Accessed $4^{\text {th }}$ June 2014.

8. WHO(2008) Weekly epidemiological Record. 83: 269-284. http://www.who.int/cholera/statistics/en/. Accessed $4^{\text {th }}$ June 2014.

9. WHO(2009) Weekly epidemiological Record. 84: 309-324. http://www.who.int/cholera/statistics/en/. Accessed $4^{\text {th }}$ June 2014

10. $\mathrm{WHO}(2010)$ Weekly epidemiological Record. 85: 293-308. http://www.who.int/cholera/statistics/en/. Accessed $4^{\text {th }}$ June 2014.

11. WHO (2011) Weekly epidemiological Record. 86: 325-340. http://www.who.int/cholera/statistics/en/. Accessed $4^{\text {th }}$ June 2014.

12. $\mathrm{WHO}(2012)$ Weekly epidemiological Record. 87: 289-304. http://www.who.int/cholera/statistics/en/. Accessed $4^{\text {th }}$ June 2014. 
13. WHO(2013) Weekly epidemiological Record. 88: 321-336. http://www.who.int/cholera/statistics/en/. Accessed $4^{\text {th }}$ June 2014.

14. WHO(2013) Outbreak Bulletin. 10: 1-8. Available: http://www.afro.who.int/en/clusters-aprogrammes/dpc/epidemic-a-pandemic-alert-andresponse/outbreak-news/3775-outbreak-bulletin-vol-2-issue10-07-february-2013.html. Accessed 4 ${ }^{\text {th }}$ June 2014.

15. WHO(2014) Global Health Observatory Data Repository. MD4:Child health: Under-five mortality. Data by Country Available: http://apps.who.int/gho/data/node.main.525. Accessed $4^{\text {th }}$ June 2014

16. Yao K, McKinney B, Murphy A, Rotz P, Wafula W, Sendagire H, Okui S, Nkengasong JN (2010) Improving quality management systems of laboratories in developing countries: an innovative training approach to accelerate laboratory accreditation. Am J Clin Pathol 134: 401-409.

17. Pal SC (1992) Laboratory Diagnosis 1st edition.New York: Plenum Publishing Corporation 229-251p.

18. Kauffman F(1966) The bacteriology of Enterobacteriaceae. $1^{\text {st }}$ edition. Copenhagen: Munksgaard 49-305p.
19. Edwards PR, Ewing WH (1962) Identification of Enterobacteriaceae. $2^{\text {nd }}$ edition. Minneapolis: Burgess Publishing Company 25-167p.

20. WHO Regional Office for Africa (2011) WHO Guide for the Stepwise Laboratory Quality Improvement Process Towards Accreditation (SLIPTA). Available: http://www.afro.who.int/en/clusters-a-programmes/hss/bloodsafety-laboratories-a-health-technology/blt-highlights/3859who-guide-for-the-stepwise-laboratory-improvement-processtowards-accreditation-in-the-african-region-withchecklist.html. Accessed $4^{\text {th }}$ June 2014.

\section{Corresponding author}

Marie Anne Chattaway

Gastrointestinal Bacteria Reference Unit, Public Health England, 61 Colindale Avenue, London, NW9 5EQ, UK

Phone: +44 (0) 2083276172

Email: marie.chattaway@phe.gov.uk

Conflict of interests: No conflict of interests is declared. 


\section{Supplementary Items}

Supplementary Figure 1. Microbiological testing flow chart for Vibrio cholera confirmation
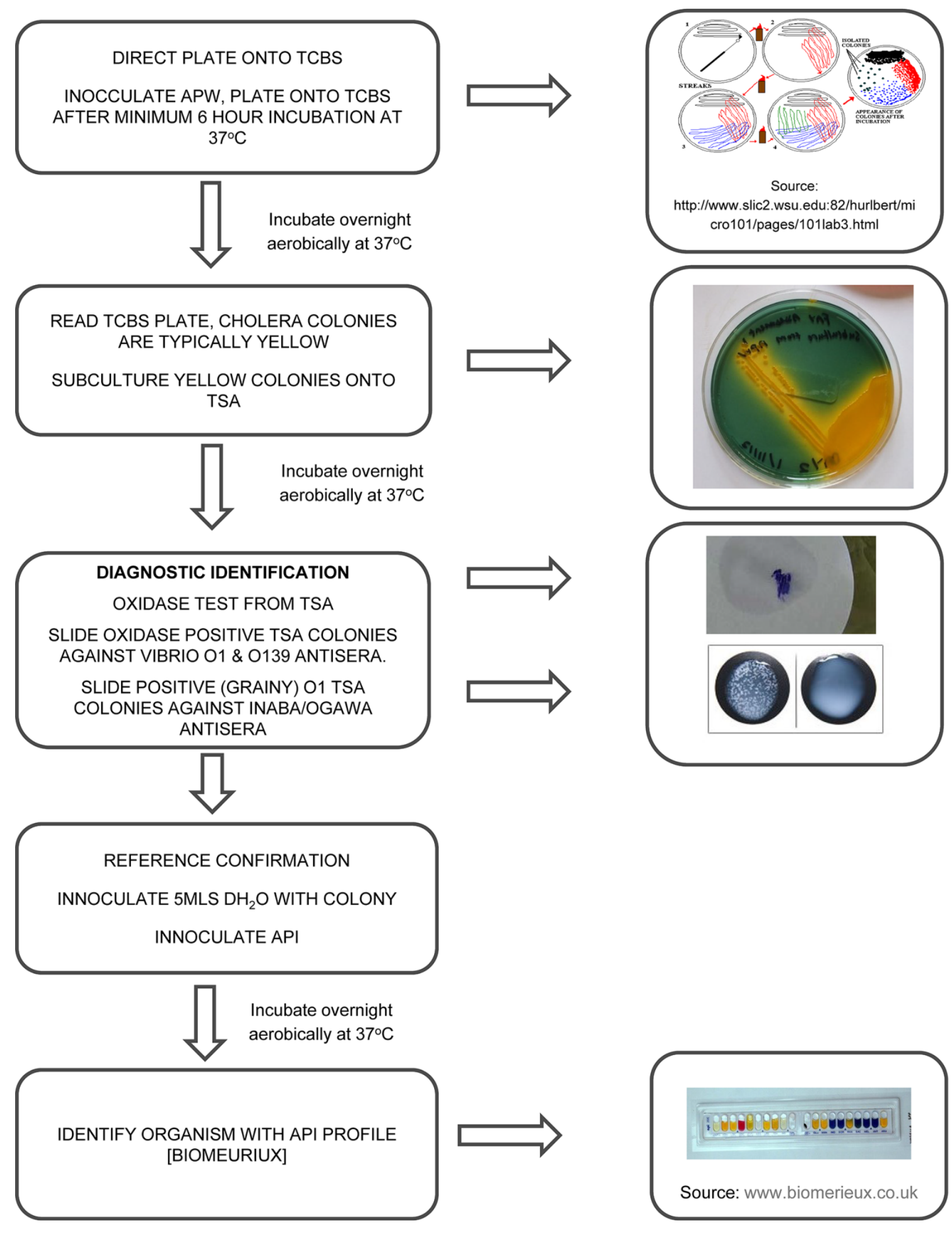
Supplementary Figure 2. Microbiological testing flow chart for Salmonella/Shigella confirmation

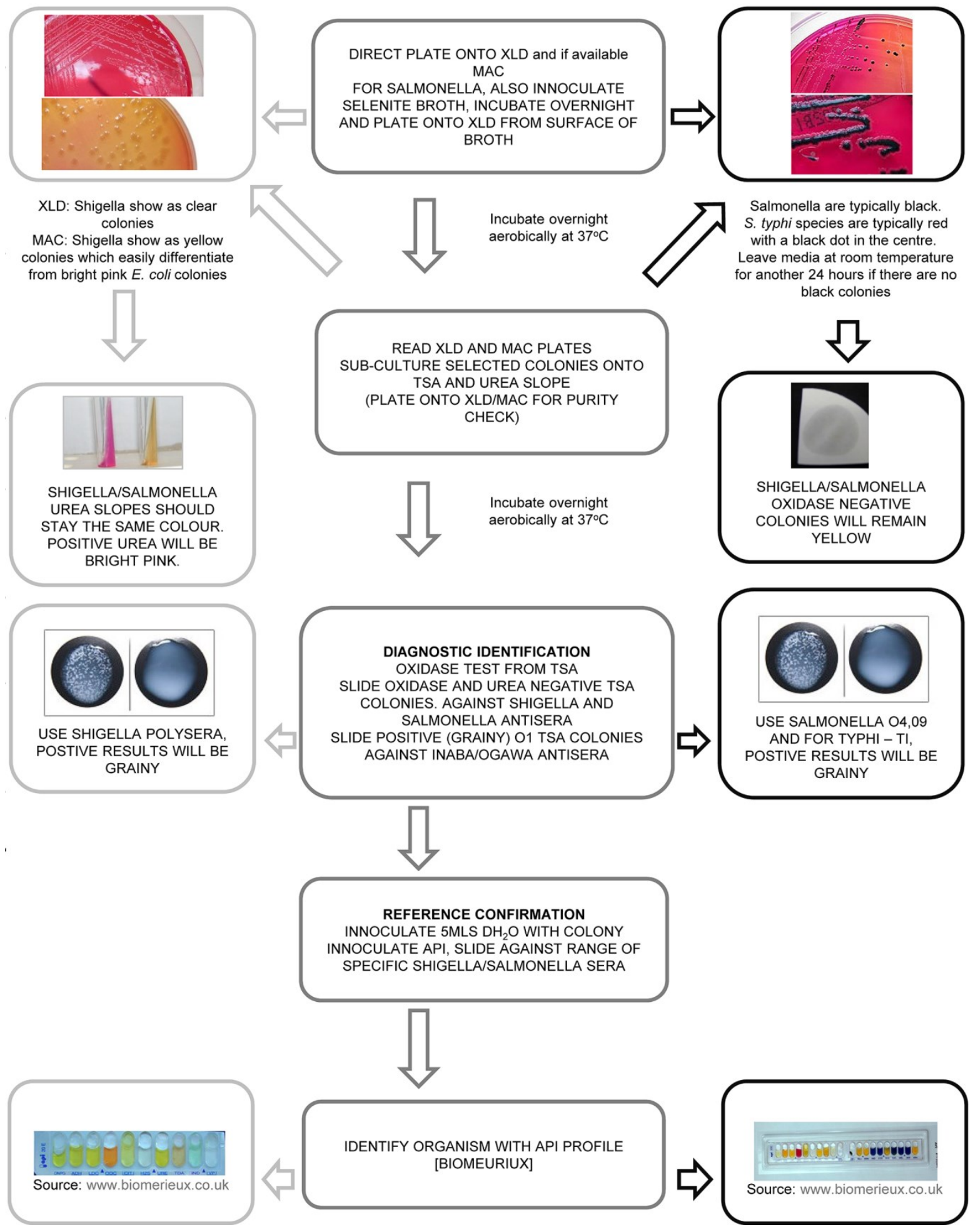

